\title{
Utilization and perioperative outcomes of robotic vaginal vault suspension compared to abdominal or vaginal approaches for pelvic organ prolapse
}

\author{
Hanhan Li, MD; Jesse Sammon, DO; ${ }^{*}$ Florian Roghmann, MD; ${ }^{\dagger}$ Akshay Sood, MD; $;^{*}$ Michael Ehlert, MD; \\ Maxine Sun, BSc; ${ }^{\dagger}$ Mani Menon, MD; ${ }^{*}$ Humphrey Atiemo, MD; ${ }^{*}$ Quoc-Dien Trinh, MD ${ }^{*}$
}

"Vattikuti Urology Institute, Henry Ford Health System, Detroit, Ml; ${ }^{\dagger}$ Cancer Prognostics and Health Outcomes Unit, University of Montreal Health Centre, Montreal, QC; ${ }^{\S}$ Department of Surgery, Division of Urology, Brigham and Women's Hospital, Harvard Medical School, Boston, MA

Dr. Li and Dr. Sammon equally contributed to this paper.

See related article on page 107.

Cite as: Can Urol Assoc J 2014;8(3-4):100-6. http://dx.doi.org/10.5489/cuaj.1858 Published online April 14, 2014.

\section{Abstract}

Objectives: Robot-assisted vaginal vault suspension (RAVVS) for pelvic organ prolapse (POP) represents a minimally-invasive alternative to abdominal sacrocolpopexy. We measured perioperative outcomes and utilization rates of RAVVS.

Methods: RAVVS ( $\mathrm{n}=2381$ ) and open VVS (OVVS, $\mathrm{n}=11080)$ data were extracted from the 2009-2010 Nationwide Inpatient Sample. Propensity score-matched analysis compared patients undergoing RAVVS or OVVS for complications, mortality, prolonged lengthof-stay, and elevated hospital charges.

Results: Use of RAVVS for POP increased from 2009 to 2010 $(16.3 \%$ to $19.2 \%)$. Patients undergoing RAVVS were more likely to be white $(77.2 \%$ vs. $69.6 \%)$, to carry private insurance $(52.8 \%$ vs. $46.0 \%$ ) and to have fewer comorbidities (Charlson Comorbidity Index $[\mathrm{CCl}] \geq 1=17.5 \%$ vs. $26.6 \%$ ). They were more likely to undergo surgery at urban $(98.2 \%$ vs. $93.7 \%)$ and academic centres (75.7\% vs. 56.7\%). Patients undergoing RAVVS were less likely to receive a blood-transfusion $(0.7 \%$ vs. $1.8 \%, p<0.001)$ or experience prolonged length-of-stay $(9.3 \%$ vs. $25.1 \%, p<0.001)$. They had more intraoperative complications $(6.0 \%$ vs. $4.2 \%, p<0.001)$, and higher median hospital charges (\$32 402 vs. \$24 136, $p<0.001)$. Overall postoperative complications were equivalent $(17.9 \%, p=1.0)$, though there were differences in wound $(0.4 \%$ vs. $1.3 \%, p<0.001)$, genitourinary $(4.9 \%$ vs. $6.5 \%, p=0.009)$, and surgical $(6.6 \%$ vs. $4.9 \%, p=0.007)$ complications.

Conclusions: The increasing use of RAVVS from 2009 to 2010 suggests a growth in the adoption of robotics to manage POP. We show that RAVVS is associated with decreased length of stay, fewer blood transfusions, as well as lower postoperative wound, genitourinary and vascular complications. The benefits of RAVVS are mitigated by higher hospital charges and higher rates of intraoperative complications.

\section{Introduction}

The lifetime risk for women to experience pelvic organ prolapse (POP) or urinary incontinence is $11.1 \% .^{1}$ It is estimated that over 200000 surgeries for POP are performed every year; $29.2 \%$ of which subsequently require revision. ${ }^{1,2}$ To determine the most effective surgical intervention for patients with POP, multiple studies have compared different approaches to vaginal vault suspension (VVS), including abdominal and transvaginal. Abdominal sacrocolpopexy (SCP) has become the gold standard for treating POP with higher relative success rates compared to a transvaginal approach. ${ }^{3,4}$ In spite of inferior durability, more transvaginal surgeries have been performed due to the higher cost and morbidity associated with abdominal SCP. 2,5,6

Recently, laparoscopic and robotic SCP have been proposed as alternatives to abdominal SCP, offering similar efficacy as the abdominal approach. They also have the added advantage of the robotic platform (decreased blood loss, length-of-stay and postoperative pain). ${ }^{7}$ However, these approaches have been slowly adopted due to cost and technical challenges. ${ }^{8-10}$

Existing robotic SCP case series, retrospective and prospective comparisons between robotic and laparoscopic or abdominal SCP are limited by small sample size and experience of a single institution/surgeon. To date, no study has described robotic utilization for POP in the United States, or nationally representative rates of perioperative morbidity and mortality. With the adoption of a robot-assisted modifier code in October 2008, we were able to examine the 20092010 Nationwide Inpatient Sample (NIS) database to report 
current trends in utilization and perioperative outcomes for robot-assisted VVS compared to open VVS (OVVS).

\section{Methods}

\section{Patient selection and variables}

Patient information was obtained from the NIS between January 2009 and December 2010 as previously described. ${ }^{11}$ In brief, the NIS includes inpatient discharge data associated with 8 million hospital discharges from more than 1000 hospitals in 44 states. This represents $20 \%$ of the public and academic hospitals within the United States.

Patients undergoing vaginal suspension and fixation and vaginal suspension and fixation with graft or prosthesis (ICD-9 [International Classification of Disease, 9th revision] procedure code 70.77 or 70.78) were extracted, yielding a weighted estimate of 13,539 patients. As recognized by the National Center of Health Statistics and the Centers for Medicare and Medicaid Services, beginning October 1, 2008, the robot-assisted modifier code (ICD-9-CM 17.4x) was introduced to identify robot-assisted VVS. Patients with the minimally-invasive modifier code (ICD-9-CM 54.21) without the robot-assisted modifier were classified as having undergone laparoscopic VVS and were removed from further analyses due to cohort size $(n=78)$. Patients who did not have robotic or minimally-invasive code were assumed to have undergone open VVS.

Patient demographics included age, race, Charlson Comorbidity Index (CCl), ${ }^{12,13}$ insurance payer, and year of surgery. Hospital information included location (rural vs. urban), geographical region, academic status, and annual caseload. Hospital-associated data were obtained from the American Hospital Association Annual Survey of Hospitals performed by the United States Census Bureau.

Outcome measures extracted from the NIS included perioperative complications, mortality during admission, requirement for blood-transfusions, length-of-stay, and total hospital charges for admission. Perioperative complications were extracted and defined using ICD-9 codes 2-15 utilizing previously described methodology. ${ }^{11,14}$ Intra-operative complications included surgical laceration of the bowel, ureter, nerves and/or vessels during a procedure (ICD-9 998.2). Blood-transfusion requirements were extracted using codes 99.02 and 99.04. Postoperative complications were identified and categorized using ICD-9 codes as previously described. ${ }^{15}$

In-hospital mortality was defined by the NIS as death occurring during admission. Length-of-stay was defined as the difference between the discharge and admission dates; it was categorized as prolonged length-of-stay if this was beyond the 75th percentile cut-off point of 2 days. Elevated hospital charges were defined as charges beyond the 75th percentile cut-off point of \$37 627 (unmatched) and \$39071 (matched).

\section{Statistical analysis}

Continuous variables were summarized by a median with interquartile ranges (IQR), while categorical variables were reported in frequencies and proportions. Pearson chi-square or Mann-Whitney $U$ tests were performed to compare categorical and continuous variables, respectively.

Propensity score matching at a 2:1 ratio was performed to account for differences in demographic characteristics between the surgical groups. ${ }^{16,17}$ Patient variables included age, race, $\mathrm{CCl}$, year of surgery and insurance status, while hospital characteristics included location, region and academic status. Trend analysis was used to determine percent change in utilization over time for each surgical group. All tests were 2-sided, with a statistical significance set at $p<0.05$. Analyses were conducted using the R statistical package v.2.15.1 (R Foundation for Statistical Computing, Vienna, Austria).

\section{Results}

From 2009 to 2010, a nationally weighted estimate of $11080(82.3 \%)$ patients underwent open VVS, whereas $2381(17.7 \%)$ underwent robot-assisted VVS. There was an increase in robot-assisted VVS utilization from $14.1 \%$ in the first quarter of 2009 to $21.8 \%$ in the fourth quarter of 2010 (Fig. 1, $p=0.025$ ).

From 2009 to 2010, utilization of VVS was assessed quarterly and an increase in robot-assisted VVS was noted compared to open VVS.

Statistical differences were noted across all demographic variables (Table 1). Patients undergoing RAVVS compared to open VVS were younger. A greater proportion of robotassisted VVS patients was white and had private insurance, while a smaller proportion of robot-assisted VVS patients had comorbidities. Robot-assisted VVS was performed at a higher proportion in teaching hospitals and urban settings. There were also noticeable regional differences in robotassisted VVS and open VVS. Specifically, robot-assisted VVS utilization was higher in the Northeast and West. Finally, median annual caseload at hospitals where patients received RAVVS was significantly higher compared to open VVS (21 [range: 7-41] vs. 9 [range: 4-20]).

Propensity-score matching (Table 2) resulted in a cohort of 4659 open VVS $(66.2 \%)$ and 2381 robot-assisted VVS $(33.8 \%)$ patients, decreasing the standardized differences between the cohorts to less than $10 \%$. The 2 hospital variables that were not used as part of the propensity matching (region and median caseload) continued to be significant- 
Li et al.

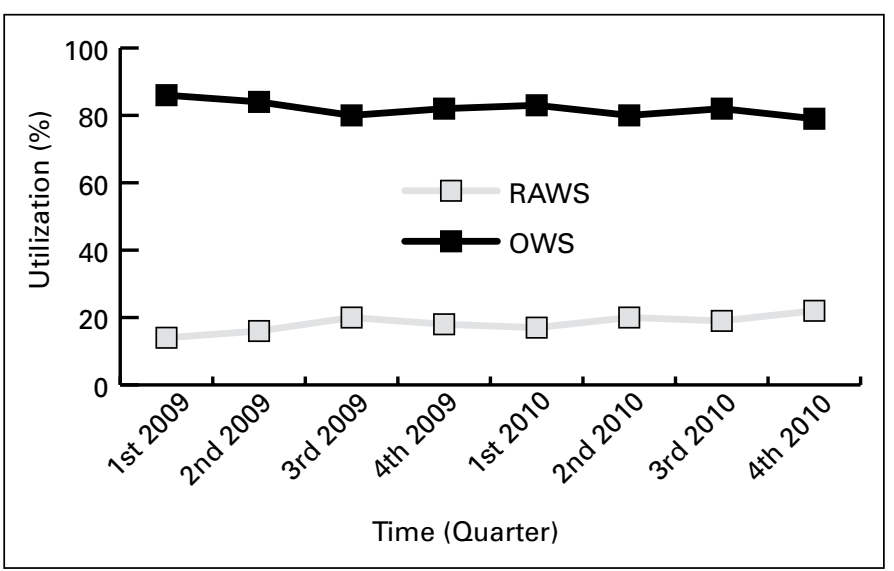

Fig. 1. Utilization of robot-assisted (RAVVS) versus open vaginal vault suspension (OVVS).

ly different between the groups, and regional differences became more noticeable.

Outcomes between the surgical groups were analyzed both in the unmatched and matched treatments (Table 3, Table 4). After propensity score matching, robot-assisted VVS had lower rates of blood transfusions and higher proportions of intraoperative complications $(6.0 \%$ vs. $4.2 \%$, $p<0.001)$. No difference in overall postoperative complications and in-hospital mortality rate was detected (Table 4).

A much higher proportion of patients undergoing open VVS stayed more than 2 days after surgery $(24.2 \%$ vs. $9.3 \%$, $p<0.001)$. However, median hospital charges were significantly lower in the open VVS population (\$24 136 [IQR: \$16 883-\$35 413] vs. \$32 402 [IQR: \$22 569-\$45 275]) compared to robot-assisted VVS patients and fewer experienced elevated hospital charges $(21.0 \%$ vs. $37.1 \%)$.

\section{Discussion}

To date, there are 2 published studies investigating trends across the United States for POP surgeries. ${ }^{2,5}$ Both studies are nearly 15 years old and pre-date the introduction of robotic surgery for VVS in $2004 .{ }^{18}$ They demonstrated that the use of a vaginal approach to vault suspension is significantly higher than abdominal SCP, despite numerous studies demonstrating decreased efficacy and the increased need for repeat surgeries. $4,6,19,20$

The current literature demonstrates that the robotic approach to VVS is effective in terms of functional outcomes, such as sexual function, pelvic organ quantification scores, mesh erosion, and rates of repeat surgery as compared to open. ${ }^{21-24}$ In addition, these studies demonstrate multiple benefits, including decreased blood loss and shorter length-of-stay. Although no prior study has been able to show significant difference in rates of transfusion, we demonstrated that a greater percentage of patients undergoing open procedures required transfusion $(1.8 \%$ vs. $0.7 \%)$ and had a prolonged length-of-stay $(24.2 \%$ vs. $9.3 \%)$, relative to patients receiving robotic surgery.

Siddiqui and colleagues demonstrated significant differences in wound complications (open $4.3 \%$ vs. robotic $0.0 \%$ ); this is similar to our own nationally representative rates (open $1.3 \%$ vs. robotic $0.4 \%$ ). ${ }^{24}$ They also demonstrated a difference in postoperative ileus (open $11.6 \%$ vs. robotic $5.6 \%)$; similarly, we show differences in the rate of medical complications, which included ileus and bowel obstruction (open $4.2 \%$ vs. robotic $3.2 \%$ ).

Our rates of intraoperative complications were higher in the robotic cohort $(6.0 \%$ vs. $4.2 \%)$ compared to open group; this suggests the influence of a learning curve implicit to the growing use of the robotic approach. Many published studies have demonstrated that operative time decreases significantly with increasing case volume, indicating that initial technical challenges are overcome with practice. ${ }^{8,25,26}$ Nonetheless, there has been no formal evaluation of the learning curve associated with robot-assisted VVS.

There are 2 analyses that studied costs associated with robotic and open approaches. Judd and colleagues presented a theoretical cost analysis demonstrating higher costs with robotic surgery compared to open surgery due to longer operating time and increased use of disposable equipment. ${ }^{10}$ This conjecture was refuted by Elliot and colleagues. ${ }^{9}$ They showed that on average the robotic approach can be more cost-effective due to lower than predicted time of robotic surgeries, the use of disposable equipment and the higher than predicted operative times for open cases. Their findings may not be widely applicable due to a relatively high proportion of robotic surgeries in their series. In either scenario, multiple factors may affect the cost-effectiveness of the robotic approach. We demonstrate that the robotic approach is associated with significantly higher hospital charges, but our analysis includes vaginal approaches which are often less expensive than abdominal approaches. In cases where patients undergoing abdominal SCP require an extended hospital stay, the robotic approach may mitigate much of the cost, due to decreased morbidity.

Of note, we found significant regional variation in the use of robot-assisted VVS. This finding may stem from surgeon preference or be driven by consumer demand, a recognized phenomenon in robotic surgery. ${ }^{27}$ We also demonstrate that patients choosing robotic surgery were more likely to be white patients with private insurance.

One of the key strengths of our study arises from the large nationally representative cohort. There has been no other study yet published examining robot-assisted VVS utilization across the United States. Furthermore, we confirm many of the purported benefits and limitations of robotic surgery, including decreased rates of blood-transfusion, decreased length-of-stay, and increased hospital charges.

While we present several novel findings, there are numer- 


\begin{tabular}{|c|c|c|c|c|}
\hline & Open & Robot-assisted & Total & $p$ value \\
\hline \multicolumn{5}{|l|}{ Patient characteristics } \\
\hline No. patients & $11080(82.3)$ & $2381(17.7)$ & 13461 & \\
\hline Median age, years (IQR) & $65(57-72)$ & $63(57-69)$ & $65(57-72)$ & $<0.001$ \\
\hline \multicolumn{5}{|l|}{ Race, n (\%) } \\
\hline White & 7717 (69.6) & $1837(77.2)$ & $9554(71.0)$ & $<0.001$ \\
\hline Black & 405 (3.7) & $62(2.6)$ & 467 (3.5) & \\
\hline Hispanic & $688(6.2)$ & $105(4.4)$ & 793 (5.9) & \\
\hline Other & $469(4.2)$ & $95(4.0)$ & $564(4.2)$ & \\
\hline Unknown & $1801(16.3)$ & $282(11.8)$ & $2083(15.5)$ & \\
\hline \multicolumn{5}{|l|}{$\mathrm{CCl}, \mathrm{n}(\%)$} \\
\hline 0 & $8134(73.4)$ & $1964(82.5)$ & $10098(75)$ & $<0.001$ \\
\hline 1 & $2474(22.3)$ & $365(15.3)$ & $2839(21.1)$ & \\
\hline 2 & 366 (3.3) & $37(1.6)$ & $403(3.0)$ & \\
\hline$\geq 3$ & $106(1.0)$ & $15(0.6)$ & $121(0.9)$ & \\
\hline \multicolumn{5}{|l|}{ Insurance status, n (\%) } \\
\hline Medicare & $5233(47.2)$ & $1000(42.0)$ & $6233(46.3)$ & $<0.001$ \\
\hline Medicaid & $316(2.9)$ & $53(2.2)$ & $369(2.7)$ & \\
\hline Private & $5102(46.0)$ & $1257(52.8)$ & $6358(47.2)$ & \\
\hline Other & 429 (3.9) & $71(3.0)$ & $500(3.7)$ & \\
\hline \multicolumn{5}{|l|}{ Year of surgery, n (\%) } \\
\hline 2009 & $5859(52.9)$ & $1142(48.0)$ & $7001(52)$ & $<0.001$ \\
\hline 2010 & $5221(47.1)$ & $1239(52.0)$ & $6461(48.0)$ & \\
\hline \multicolumn{5}{|l|}{ Hospital characteristics of patient } \\
\hline \multicolumn{5}{|l|}{ Academic status, $\mathrm{n}(\%)$} \\
\hline Nonteaching & $4798(43.3)$ & $578(24.3)$ & $5371(39.9)$ & $<0.001$ \\
\hline Teaching & $6282(56.7)$ & $1803(75.7)$ & $8085(60.1)$ & \\
\hline \multicolumn{5}{|l|}{ Location, n (\%) } \\
\hline Rural & $811(7.3)$ & $42(1.8)$ & 848 (6.3) & $<0.001$ \\
\hline Urban & $10269(92.7)$ & $2339(98.2)$ & $12608(93.7)$ & \\
\hline \multicolumn{5}{|l|}{ Region, n (\%) } \\
\hline Northeast & $2019(18.2)$ & $667(28.0)$ & $2686(20.0)$ & $<0.001$ \\
\hline Midwest & $2715(24.5)$ & $453(19.0)$ & 3168 (23.5) & \\
\hline South & 3907 (35.3) & $702(29.5)$ & 4609 (34.2) & \\
\hline West & $2439(22.0)$ & $559(23.5)$ & $2998(22.3)$ & \\
\hline Median annual caseload, n (IQR) & $9(4-20)$ & $21(7-41)$ & $10(4-23)$ & $<0.001$ \\
\hline
\end{tabular}

ous limitations associated with population-based analyses that restrict the utility of our findings. It would have been ideal to compare robotic SCP with open abdominal or vaginal SCP, but the ICD-9-CM codes do not distinguish between vaginal or abdominal approaches to vault suspension. Additionally, the NIS is unable to provide information prior to or beyond the index hospital admission; accordingly data on initial diagnoses, such as severity and type of prolapse, reasons for pursuing robotic vs. open surgical treatments, or follow-up for symptomatic improvement, are not available. Additional limitations stem from the finding that the 2 cohorts were statistically different prior to matching, but this is likely due to the very high numbers in each cohort. These differences were mitigated through propensity-score matched analysis.

\section{Conclusion}

Our analysis describes previously unpublished findings concerning the trends in utilization across the United States of robot-assisted VVS in the treatment of female POP. We demonstrate, in a nationally representative sample, consistent trends of decreased length-of-stay and decreased rates of transfusion associated with robotic surgery. We also confirm the additional associated cost. Prospective studies examin- 
Li et al.

\begin{tabular}{|c|c|c|c|c|}
\hline & Open & Robot-assisted & Total & $p$ value \\
\hline \multicolumn{5}{|l|}{ Patient characteristics } \\
\hline No. patients (\%) & $4659(66.2)$ & $2381(33.8)$ & 7040 & \\
\hline Median age, years (IQR) & $63(57-63)$ & $63(57-69)$ & $63(57-70)$ & 0.234 \\
\hline \multicolumn{5}{|l|}{ Race, n (\%) } \\
\hline White & $3541(76.0)$ & $1837(77.2)$ & $5378(76.4)$ & 0.010 \\
\hline Black & $140(3.0)$ & $62(2.6)$ & $202(2.9)$ & \\
\hline Hispanic & $224(4.8)$ & $105(4.4)$ & $330(4.7)$ & \\
\hline Other & $126(2.7)$ & $95(4.0)$ & $221(3.1)$ & \\
\hline Unknown & $628(13.5)$ & $282(11.8)$ & $910(12.9)$ & \\
\hline \multicolumn{5}{|l|}{$\mathrm{CCl}, \mathrm{n}(\%)$} \\
\hline 0 & $3924(84.2)$ & 1964 (82.5) & $5888(83.6)$ & 0.138 \\
\hline 1 & $650(14.0)$ & $365(15.3)$ & $1014(14.4)$ & \\
\hline 2 & $69(1.5)$ & $37(1.6)$ & $106(1.5)$ & \\
\hline$\geq 3$ & $16(0.3)$ & $15(0.6)$ & $31(0.4)$ & \\
\hline \multicolumn{5}{|l|}{ Insurance status, n (\%) } \\
\hline Medicare & $2029(43.6)$ & $1000(42.0)$ & $3029(43.0)$ & 0.554 \\
\hline Medicaid & $113(2.4)$ & $53(2.2)$ & $166(2.4)$ & \\
\hline Private & $2377(51.0)$ & $1257(52.8)$ & $3632(51.6)$ & \\
\hline Other & $140(3.0)$ & $71(3.0)$ & $211(3.0)$ & \\
\hline \multicolumn{5}{|l|}{ Year of surgery, n (\%) } \\
\hline 2009 & $2252(48.3)$ & $1142(48.0)$ & $3394(48.2)$ & 0.782 \\
\hline 2010 & $2407(51.7)$ & $1239(52.0)$ & $3646(51.8)$ & \\
\hline \multicolumn{5}{|l|}{ Hospital characteristics of patient } \\
\hline \multicolumn{5}{|l|}{ Academic status, n (\%) } \\
\hline Nonteaching & 1140 (24.5) & $578(24.3)$ & $1717(24.4)$ & 0.883 \\
\hline Teaching & 3519 (75.5) & $1803(75.7)$ & $5322(75.6)$ & \\
\hline \multicolumn{5}{|l|}{ Location, n (\%) } \\
\hline Rural & $95(2.0)$ & $42(1.8)$ & $137(1.9)$ & 0.466 \\
\hline Urban & $4564(98.0)$ & $2339(98.2)$ & $6903(98.1)$ & \\
\hline \multicolumn{5}{|l|}{ Region, n (\%) } \\
\hline Northeast & $1157(24.8)$ & $667(28.0)$ & $1824(25.9)$ & $<0.001$ \\
\hline Midwest & $1073(23.0)$ & $453(19.0)$ & $1525(21.7)$ & \\
\hline South & 1619 (34.8) & $702(29.5)$ & 1369 (19.4) & \\
\hline West & $810(17.4)$ & $559(23.5)$ & $1369(19.4)$ & \\
\hline Median annual caseload, n (IQR) & $13(6-24)$ & $21(7-41)$ & $14(6-29)$ & $<0.001$ \\
\hline
\end{tabular}

ing robotic SCP long-term functional outcomes are needed and are underway. ${ }^{28}$ We believe that these studies will support the practice of robotic surgery, which has demonstrated advantages and is growing in utilization.

Competing interests: Dr. Li, Dr. Sammon, Dr. Roghmann, Dr. Sood, Dr. Ehlert, Dr. Sun, Dr. Menon and Dr. Atiemo all declare no competing financial or personal interests. Dr. Trinh has received consultant fees from Intuitive Surgical.

This paper has been peer-reviewed.

\section{References}

1. Olsen AL, Smith VJ, Bergstrom J0, et al. Epidemiology of surgically managed pelvic organ prolapse and urinary incontinence. Obstet Gynecol 1997;89:501-6. http://dx.doi.org/10.1016/S00297844(97)00058-6

2. Boyles SH, Weber AM, Meyn L. Procedures for pelvic organ prolapse in the United States, 1979-1997. Am J Obstet Gynecol 2003;188:108-15. http://dx.doi.org/10.1067/mob.2003.101

3. Maher C, Baessler K, Glazener $C M$, et al. Surgical management of pelvic organ prolapse in women: A short version Cochrane review. Neurourol Urodyn 2008;27:3-12. http://dx.doi.org/10.1002/nau.20542

4. Nygaard IE, McCreery R, Brubaker L, et al. Abdominal sacrocolpopexy: A comprehensive review. Obstet Gynecol 2004;104:805-23. http://dx.doi.org/10.1097/01.A0G.0000139514.90897.07

5. Brown JS, Waetjen LE, Subak LL, et al. Pelvic organ prolapse surgery in the United States, 1997. Am J Obstet Gynecol 2002;186:712-6. http://dx.doi.org/10.1067/mob.2002.121897 


\begin{tabular}{|c|c|c|c|c|}
\hline & Open & Robot-assisted & Total & $p$ value \\
\hline No. patients & 11080 & 2381 & 13461 & \\
\hline Blood transfusion, n (\%) & $198(1.8)$ & $16(0.7)$ & $214(1.6)$ & $<0.001$ \\
\hline Intraoperative complication, n (\%) & $465(4.2)$ & $143(6.0)$ & $608(4.5)$ & $<0.001$ \\
\hline \multicolumn{5}{|l|}{ Postoperative complication, n (\%) } \\
\hline Overall & $2148(19.4)$ & 427 (17.9) & $2575(19.1)$ & 0.108 \\
\hline Cardiac & $342(3.1)$ & $58(2.4)$ & $400(3.0)$ & 0.099 \\
\hline Vascular & $76(0.7)$ & $5(0.2)$ & $81(0.6)$ & 0.008 \\
\hline Operative wound & $159(1.4)$ & $10(0.4)$ & 169 (1.3) & $<0.001$ \\
\hline Genitourinary & $890(8.0)$ & $117(4.9)$ & $1007(7.5)$ & $<0.001$ \\
\hline Neurological & $76(0.7)$ & $26(1.1)$ & $102(0.8)$ & 0.045 \\
\hline Infection & $41(0.4)$ & $5(0.2)$ & $46(0.3)$ & 0.331 \\
\hline Miscellaneous medical & $495(4.5)$ & $75(3.2)$ & $570(4.2)$ & 0.004 \\
\hline Miscellaneous surgical & $544(4.9)$ & $157(6.6)$ & $701(5.2)$ & 0.001 \\
\hline In-hospital mortality, n (\%) & $4(0.0)$ & $5(0.2)$ & $9(0.1)$ & 0.012 \\
\hline Length of stay $\geq 2$ days, $n(\%)$ & $2783(25.1)$ & $222(9.3)$ & $3005(22.3)$ & $<0.001$ \\
\hline Total admission charge $\geq \$ 37627, \mathrm{n}(\%)$ & $2430(21.9)$ & $883(37.1)$ & $3313(24.6)$ & $<0.001$ \\
\hline Median annual caseload, $\mathrm{n}$ (IQR) & $9(4-20)$ & $21(7-41)$ & $10(4-23)$ & $<0.001$ \\
\hline
\end{tabular}

\begin{tabular}{|c|c|c|c|c|}
\hline & Open & Robot-assisted & Total & $p$ value \\
\hline No. patients & 4660 & 2381 & 7041 & \\
\hline Blood transfusion, n (\%) & $86(1.8)$ & $16(0.7)$ & $102(1.4)$ & $<0.001$ \\
\hline Intra-operative complication, n (\%) & $195(4.2)$ & $143(6.0)$ & $338(4.8)$ & 0.001 \\
\hline \multicolumn{5}{|l|}{ Postoperative complication, n (\%) } \\
\hline Overall & $835(17.9)$ & $427(17.9)$ & $1262(17.9)$ & 1.0 \\
\hline Cardiac & $132(2.8)$ & $58(2.4)$ & $190(2.7)$ & 0.352 \\
\hline Vascular & $31(0.7)$ & $5(0.2)$ & $36(0.5)$ & 0.012 \\
\hline Operative wound & $60(1.3)$ & $10(0.4)$ & $70(1.0)$ & $<0.001$ \\
\hline Genitourinary & $301(6.5)$ & $117(4.9)$ & $418(5.9)$ & 0.009 \\
\hline Neurological & $49(1.1)$ & $26(1.1)$ & $75(1.1)$ & 0.903 \\
\hline Infection & $15(0.3)$ & $5(0.2)$ & $20(0.3)$ & 0.485 \\
\hline Miscellaneous medical & $195(4.2)$ & $75(3.2)$ & $270(3.8)$ & 0.036 \\
\hline Miscellaneous surgical & $234(5.0)$ & $157(6.6)$ & $391(5.6)$ & 0.007 \\
\hline In-hospital mortality, n (\%) & $4(0.1)$ & $5(0.2)$ & $9(0.1)$ & 0.177 \\
\hline Length of stay $\geq 2$ days, $n$ (\%) & $1129(24.2)$ & 222 (9.3) & $1351(19.2)$ & $<0.001$ \\
\hline Total admission charge $\geq \$ 39071, \mathrm{n}(\%)$ & $977(21.0)$ & $883(37.1)$ & $1860(26.4)$ & $<0.001$ \\
\hline Median annual caseload, $\mathrm{n}$ (IQR) & $9(4-20)$ & $21(7-41)$ & $10(4-23)$ & $<0.001$ \\
\hline
\end{tabular}

6. Brubaker L. Surgery for pelvic organ prolapse. In: Abrams P, Cardozo L, Khoury S, Wein A, eds. Incontinence: Management. Vol 2. Paris: International Continence Society Health Publication Ltd; 2005:1371-402.

7. Xylinas E, Ouzaid I, Durand X, et al. Robot-assisted laparoscopic sacral colpopexy: Initial experience in a high-volume laparoscopic reference center. J Endourol 2010;24:1985-9.

8. Daneshgari F, Kefer JC, Moore C, et al. Robotic abdominal sacrocolpopexy/sacrouteropexy repair of advanced female pelvic organ prolaspe (POP): Utilizing POP-quantification-based staging and outcomes. BJU Int 2007;100:875-9. http://dx.doi.org/10.1111/i.1464-410X.2007.07109.x

9. Elliott CS, Hsieh MH, Sokol ER, et al. Robot-assisted versus open sacrocolpopexy: A cost-minimization analysis. J Urol 2012;187:638-43. http://dx.doi.org/10.1016/i.juro.2011.09.160

10. Judd JP, Siddiqui NY, Barnett JC, et al. Cost-minimization analysis of robotic-assisted, laparoscopic, and abdominal sacrocolpopexy. J Minim Invasive Gynecol 2010;17:493-9. http://dx.doi.org/10.1016/i. imig.2010.03.011
11. Antczak C, Trinh VQ, Sood A, et al. The health care burden of skeletal related events in patients with renal cell carcinoma with bone metastasis. J Urol 2013 Dec 30. http://dx.doi.org/10.1016/i. juro.2013.12.042

12. Charlson ME, Pompei P, Ales KL, et al. A new method of classifying prognostic comorbidity in longitudinal studies: Development and validation. J Chronic Dis 1987;40:373-83. http://dx.doi.org/10.1016/00219681(87)90171-8

13. Deyo RA, Cherkin DC, Ciol MA. Adapting a clinical comorbidity index for use with ICD-9-CM administrative databases. J Clinical Epidemiol 1992;45:613-9. hittp://dx.doi.org/10.1016/0895-4356(92)90133-8

14. Hu JC, Wang $Q$, Pashos $\mathrm{CL}$, et al. Utilization and outcomes of minimally invasive radical prostatectomy. $J$ Clin Oncol 2008;26:2278-84.

15. Hu JC, Gu X, Lipsitz SR, et al. Comparative effectiveness of minimally invasive vs open radical prostatectomy. JAMA 2009;302:1557-64. http://dx.doi.org/10.1001/jama.2009.1451 
Li et al.

16. D'Agostino RB Jr. Propensity score methods for bias reduction in the comparison of a treatment to a non-randomized control group. Stat Med 1998;17:2265-81. http://dx.doi.org/10.1002/(SICI) 10970258(19981015) 17:19<2265::AID-SIM918>3.0.C0;2-B

17. Stukel TA, Fisher ES, Wennberg DE, et al. Analysis of observational studies in the presence of treatment selection bias: Effects of invasive cardiac management on AMI survival using propensity score and instrumental variable methods. JAMA 2007;297:278-85. http://dx.doi.org/10.1001/jama.297.3.278

18. Di Marco DS, Chow GK, Gettman MT, et al. Robotic-assisted laparoscopic sacrocolpopexy for treatment of vaginal vault prolapse. Urology 2004;63:373-6. http://dx.doi.org/10.1016/j.urology.2003.09.033

19. Benson AD, Kramer BA, Wayment RO, et al. Supracervical robotic-assisted laparoscopic sacrocolpopexy for pelvic organ prolapse. JSLS 2010;14:525-30.

20. Maher $C$, Baessler $\mathrm{K}$, Glazener $C M$, et al. Surgical management of pelvic organ prolapse in women. Cochrane Database Syst Rev 2004:CD004014.

21. Collins SA, Tulikangas PK, O'Sullivan DM. Effect of surgical approach on physical activity and pain control after sacral colpopexy. Am J Obstet Gynecol 2012;206:438 e431-6.

22. Geller EJ, Parnell BA, Dunivan GC. Robotic vs abdominal sacrocolpopexy: 44-month pelvic floor outcomes. Urology 2012;79:532-6. http://dx.doi.org/10.1016/i.urology.2011.11.025

23. Geller EJ, Siddiqui NY, Wu JM, et al. Short-term outcomes of robotic sacrocolpopexy compared with abdominal sacrocolpopexy. Obstet Gynecol 2008;112:1201-6. http://dx.doi.org/10.1097/ AOG.0b013e31818ce394

24. Siddiqui NY, Geller EJ, Visco AG. Symptomatic and anatomic 1-year outcomes after robotic and abdominal sacrocolpopexy. Am J Obstet Gynecol 2012;206:435, el-5.

25. Germain $A$, Thibault $F$, Galifet $M$, et al. Long-term outcomes after totally robotic sacrocolpopexy for treatment of pelvic organ prolapse. Surg Endosc 2013;27:525-9. http://dx.doi.org/10.1007/s00464012-2472-4. Epub 2012 Jul 18.
26. Moreno Sierra J, Ortiz Oshiro E, Fernandez Perez C, et al. Long-term outcomes after robotic sacrocolpopexy in pelvic organ prolapse: Prospective analysis. Urologia Int 2011;86:414-8. http://dx.doi. org/10.1159/000323862

27. Schiavone MB, Kuo EC, Naumann RW, et al. The commercialization of robotic surgery: unsubstantiated marketing of gynecologic surgery by hospitals. Am J Obstet Gynecol 2012;207:174.el-7. http://dx.doi. org/10.1016/i.ajog.2012.06.050. Epub 2012 Jun 29.

28. Mueller ER, Kenton K, Tarnay C, et al. Abdominal colpopexy: Comparison of endoscopic surgical strategies (ACCESS). Contemp Clin Trials 2012;33:1011-8. http://dx.doi.org/10.1016/i.cct.2012.05.007

Correspondence: Dr. Akshay Sood, Vattikuti Urology Institute, Henry Ford Health System, 2799 West Grand Blvd, Detroit, MI - 48202; fax: 313-916-4352; asood1@hfhs.org

\begin{tabular}{lc}
\hline Appendix 1. ICD-9 codes utilized & \\
\hline Patient selection & \\
\hline Vaginal vault suspension & $70.77,70.78$ \\
Robot-assisted modifier & $17.4 \mathrm{x}$ \\
Minimally-invasive modifier & 54.21 \\
Intraoperative complications & 998.2 \\
Blood-transfusion & $99.02,99.04$ \\
\hline ICD: International Classification of Diseases. \\
All other ICD-9 codes can be found in Hu et al. ${ }^{14}$
\end{tabular}

